\title{
Analisa Kebutuhan Ruang Parkir Kendaraan Pada Hotel Swiss-Bell di Kota Jambi
}

\author{
Rizky Ananda T ${ }^{\mathbf{1}}$, Fahrul Rozi Yamali ${ }^{2}$, Kiki Rizky Amalia ${ }^{3}$ \\ ${ }^{1}$ Mahasiswa Teknik Sipil Universitas Batanghari Jambi \\ ${ }^{2,3}$ Dosen Fakultas Teknik Universitas Batanghari Jambi \\ Correspondence email: iqy.amalia@gmail.com
}

\begin{abstract}
Abstrak. Pada umumnya fasilitas kebutuhan masyarakat memerlukan sarana tempat parkir yang nyaman dan efisien, salah satunya pada Hotel Swiss-Bell di Kota Jambi. Kebutuhan parkir yang tidak terpenuhi, dapat menimbulkan masalah lalulintas karena pengguna badan jalan untuk lahan parkir (on street parking) sehingga menyebabkan kemacetan karena penggunaan kapasitas jalan dan terganggunya fungsi jalan. Metode survei yang diterapkan pada penelitian ini adalah dengan melakukan survei langsung ke lapangan yaitu dangan cara mencatat nomor kendaraan yang masuk dan keluar beserta waktu masuk dan keluar kendaraan dari tempat parkir. Pencatatan nomor kendaran yang masuk dan keluar dapat dilakukan di daerah pintu masuk dan keluar fasilitas parkir, yang dapat dilakukan pengelompokan tiap 10 menit atau pencatatan langsung waktu masuk dan keluar kendaraan. Dari data kendaraan dilakukan analisa untuk mendapatkan akumulasi parkir, durasi parkir, kapasitas parkir dan indeks parkir. Berdasarkan perhitungan kebutuhan ruang parkir di Hotel Swiss-Bell untuk kendaraan roda dua jumlah ruang parkir yang disediakan 150 ruang parkir dengan luas ruang parkir $225 \mathrm{~m}^{2}$ mampu melayani kapasitas parkir sebesar $195 \mathrm{kendaraan} / \mathrm{hari}$ dan untuk kendaraan roda empat jumlah ruang parkir yang di sediakan 80 ruang parkir dengan luas $1000 \mathrm{M}^{2}$ mampu melayani kapasitas parkir sebesar 118 kendaraan/hari. Ini menunjukan kapasitas parkir untuk kendaraan roda empat harus ada penambahan lahan parkir sebesar $275 \mathrm{M}^{2}$ agar mampu menampung kendaraan yang parkir sebesar 118 kendaraan.
\end{abstract}

Kata kunci: Parkir, Hotel Swiss-Bell, Jambi

\section{PENDAHULUAN}

Seiring dengan semakin meningkatnya pertumbuhan penduduk serta tinginya tingkat perekonomian di suatu perkotaan atau meningkatnya suatu perkotaan menuju suatu kota metropolitan maka akan mengakibatkan meningkatnya kebutuhan akan fasilitas-fasilitas yang dibutuhkan oleh masyarakat kota seperti perhotelan, pusat bisnis, pendidikan, perkantoran, maupun perdagangan. Kecenderungan peningkatan pengguna kendaraan pribadi ini akan meningkatkan kebutuhan akan fasilitas ruang parkir juga turut meningkat. Kebutuhan parkir yang tidak terpenuhi inilah yang dapat menimbulkan masalah lalulintas karena pengguna badan jalan untuk kebutuhan lahan parkir (on street parking) dengan kata lain dapat menyebabkan kemacetan karena pengguna kapasitas jalan dan terganggunya fungsi jalan. Untuk menghindarkan terjadinya kemacetan tersebut maka diharapkan pusat perhotelan, pusat bisnis, pendidikan, perkantoran, maupun perdagangan dapat menyediakan tempat parkir kendaraan tersendiri (Fauziah Syarifudin, 2017).

Oleh sebab itu pelayanan parkir yang nyaman dan efisien merupakan salah satu pelayanan yang harus dipenuhi oleh setiap pusat kegiatan manapun termasuk Hotel Swiss-Bell karena sudah merupakan penunjang kelancaran kegiatan yang membantu pola perkembangan wilayah. Bila tidak ada kontribusi untuk mengatasi permasalahan tersebut maka akan terjadi parkir dibadan jalan yang akan mengakibatkan kemacetan karena pengurangan kapasitas jalan. Untuk itu perlu dilakukan penelitian kondisi ruang parkir Hotel Swiss-Bell guna untuk mengetahui kapasitas ruang parkir kemudian dievaluasi secara lebih lanjut sehingga menghasilkan parkir yang efesien yang mampu menampung jumlah kendaraan yang ada. Berdasarkan pendahuluan yang dilakukan peneliti di Hotel Swiss-Bell jumlah lahan parkir seluas $1225 \mathrm{~m}^{2}$ mampu menampung 80 kendaraan mobil penumpang dan kendaraan sepeda motor 150 kendaraan.

\section{Pengertian perhotelan}

Menurut Sri Perwani, (2007). Kata hotel mulai dipakai sejak abad ke 18 di London, Inggris, Pada saat itu kata hotel adalah " garni " sebuah rumah besar yang dilengkapi dengan sarana tempat menginap atau tempat tinggal untuk penyewaan secara harian, mingguan atau bulanan. Hotel adalah bangunan yang menyediakan kamar-kamar untuk menginap para tamu makan dan minuman, serta fasilitas-fasilitas lain yang diperlukan dan dikelola secara profesonal untuk mendapatkan keuntungan ( Sri Perwani, 2007).

\section{Pengertian parkir}

Menurut A.A. Jaya Wikrama,(2010 ) Parkir adalah keadaan tidak bergerak suatu kendaraan yang bersifat sementara karena ditinggalkan oleh pengemudinya. Setiap pengendara kendaraan bermotor memiliki kecendrungan untuk mencari tempat untuk memakirkan kendaraannya sedekat mungkin dengan tempat kegiatan atau tempat 
beraktifitas. Sehingga tempat-tempat terjadinya suatu kegiatan di salah satu tempat perhotelan diperlukan tempat areal parkir yang cukup untuk menampung kendaraan yang hendak perkir di lokasi tersebut.

\section{Satuan Ruang Parkir}

Menurut Direktur Jendral Perhubungan Darat,(1996) dalam Ahmad Munawar (2014) Satuan ruang parkir (SRP) adalah ukuran luas efektif untuk meletakkan suatu kendaraan (mobil penumpang, atau sepeda motor) termasuk ruang bebas dan lebar bukaan pintu.

Penentuan Satuan Ruang Parkir (SRP) berdasarkan pada pertimbangan hal sebagai berikut:

\section{Dimensi kendaraan Standar}

Dimensi kendaraan standar untuk mobil penumpang pada Gambar 1.

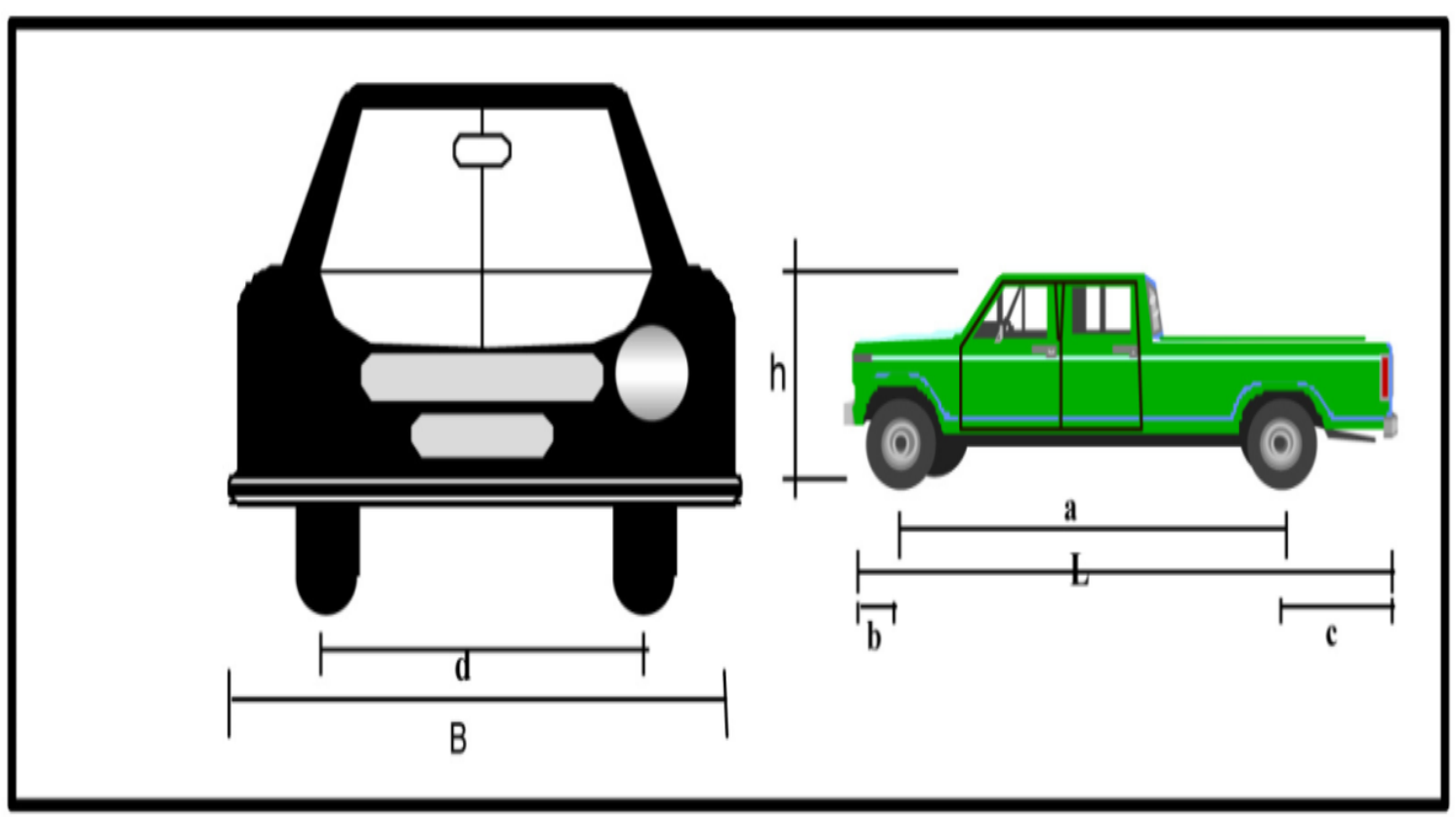

Sumber: Menurut Direktur Jenderal Perhubungan Darat,(1996) dalam Ahmad Munawar (2014)

Gambar 1. Dimensi kendaraan standar untuk mobil penumpang

\section{Ruang bebas kendaraan parkir}

Ruang bebas kendaraan parkir diberikan pada arah lateral dan longitudinal kendaraan. Ruang bebas arah lateral ditetapkan pada saat posisi pintu kendaraan dibuka, yang diukur dari ujung paling luar pintu ke badan kendaraan yang parkir di samping Menurut Direktur Jenderal Perhubungan Darat,(1996) dalam Ahmad Munawar (2014) Ruang bebas ini diberikan agar tidak terjadi benturan antara pintu kendaraan dengan kendaraan yang parkir disampingnya pada saat penumpang turun dari kendaraan. Ruang bebas arah memanjang atau longitudinal diberikan di depan kendaraan untuk menghindari benturan dengan dinding atau kendaraan yang lewat gang ( aisle ). Jarak bebas arah lateral diambil sebesar $5 \mathrm{~cm}$ dan jarak bebas arah longitudinal sebesar $30 \mathrm{~cm}$.

\section{Satuan Ruang Parkir}

Tabel 1. Penentuan satuan ruang parkir (SRP)

\begin{tabular}{clc}
\hline No & \multicolumn{1}{c}{ Jenis Kendaraan } & Satuan Ruang parkir (M) \\
\hline & a. Mobil Penumpang Untuk Golongan I & $2,30 \times 5,00$ \\
1 & b. Mobil Penumpang Untuk Golongan II & $2,50 \times 5,00$ \\
& c. Mobil Penumpang Untuk Golongan III & $3,00 \times 12,5$ \\
2 & Bus Atau Truk & $3,40 \times 12,5$ \\
3 & Sepeda Motor & $0,75 \times 2,00$ \\
\hline
\end{tabular}

Sumber: Direktur Jendral Perhubungan Darat,(1996) dalam Ahmad Munawar (2014)

\section{Teori Analisa Parkir}

Dalam upaya menganalisa masalah parkir, perlu dilakukan pengumpulan data parkir dengan melakukan survai pengukuran di lapangan, menurut I.N. Karuna Putra (2007) informasi tersebut di atas diperlukan dalam rangka 
perencanaan fasilitas parkir, atau pengaturan parkir yang sudah ada. Dengan survai ini didapatkan data Durasi, Akumulasi parkir dan Indekasi parkir.

1. Akumulasi parkir

Menurut Lindawati MZ (2012) Akumulasi parkir adalah jumlah kendaraan yang parkir pada saat tertentu, di suatu tempat gedung parkir atau pelataran parkir.

Untuk menghitung akumulasi parkir dipergunakan persamaan sebagai berikut :
Akumulasi $=E i-E x$
Dimana
Ei $\quad=$ Entri $($ kendaraan yang masuk lokasi)
Ex $\quad=$ Extime (kendaraan yang keluar lokasi)

Jika sebelum diadakan pengamatan, sudah ada kendaraan yang parkir dilokasi survei, maka jumlah kendaraan yang ada tersebut dijumlahkan dalam harga akumulasi yang disebut yaitu :

Akumulasi $=E i-E x+x$

Dimana,

$\mathrm{X} \quad=$ jumlah kendaraan yang sudah ada

2. Durasi parkir

Menurut Lindawati MZ (2012) Durasi parkir adalah rentang waktu sebuah kendaraan parkir dalam menit atau jam.

Durasi parkir dihitung dengan persamaan:

Durasi $=$ Extime - Entime

Dimana,

Extime $\quad=$ Saat kendaraan keluar dari lokasi parkir

Entime $\quad=$ Saat kendaraan masuk lokasi parkir

\section{Analisa data parkir}

1. Kapasitas parkir

Menurut Dewi Sakti (2011) Kapasitas parkir adalah jumlah kendaraan yang dapat ditampung oleh suatu area parkir atau jumlah petak parkir yang tersedia pada suatu area parkir.

Rumus-rumus yang dipergunakan dalam perhitungan analisa kapasitas parkir yang ada diambil dari pignatoro, L.J.,(1973) dalam Dewi Sakti (2011) antara lain :

$\mathrm{KD}=\mathrm{KS} \times(\mathrm{P} / \mathrm{D})$

Dimana,

KD = Kapasitas parkir kendaraan dalam jam survei (kendaraan)

$\mathrm{KS} \quad=$ Jumlah ruang parkir yang ada (kendaraan)

$\mathrm{P} \quad$ = Lama survei (jam)

$\mathrm{D}=$ Durasi parkir (jam)

Jumlah ruang parkir yang dibutuhkan :

$\mathrm{Z} \quad=\frac{\mathrm{Y} \times \mathrm{D}}{\mathrm{P}}$

Dimana,

$\mathrm{Z} \quad$ = Ruang parkir yang dibutuhkan (kendaraan)

$\mathrm{Y} \quad=$ Jumlah kendaraan yang parkir dalam satu waktu

$\mathrm{D} \quad=$ Durasi parkir (jam)

$\mathrm{P} \quad=$ Lama survei $(\mathrm{jam})$

2. Indeks parkir

Menurut Dewi Sakti (2011) Indeks parkir adalah prosentase jumlah tempat parkir yang disediakan (secara teoritis) dengan jumlah kendaraan parkir yang menempati (yang terjadi). Indeks parkir dihitung dengan persamaan:

Indeks parkir $\quad=\frac{\text { Akumulasi parkir }}{\text { Ruang parkir tersedia }}$......... 


\section{METODE}

Secara ringkas, penelitian ini bisa dilihat dari bagan alir penelitian berikut:

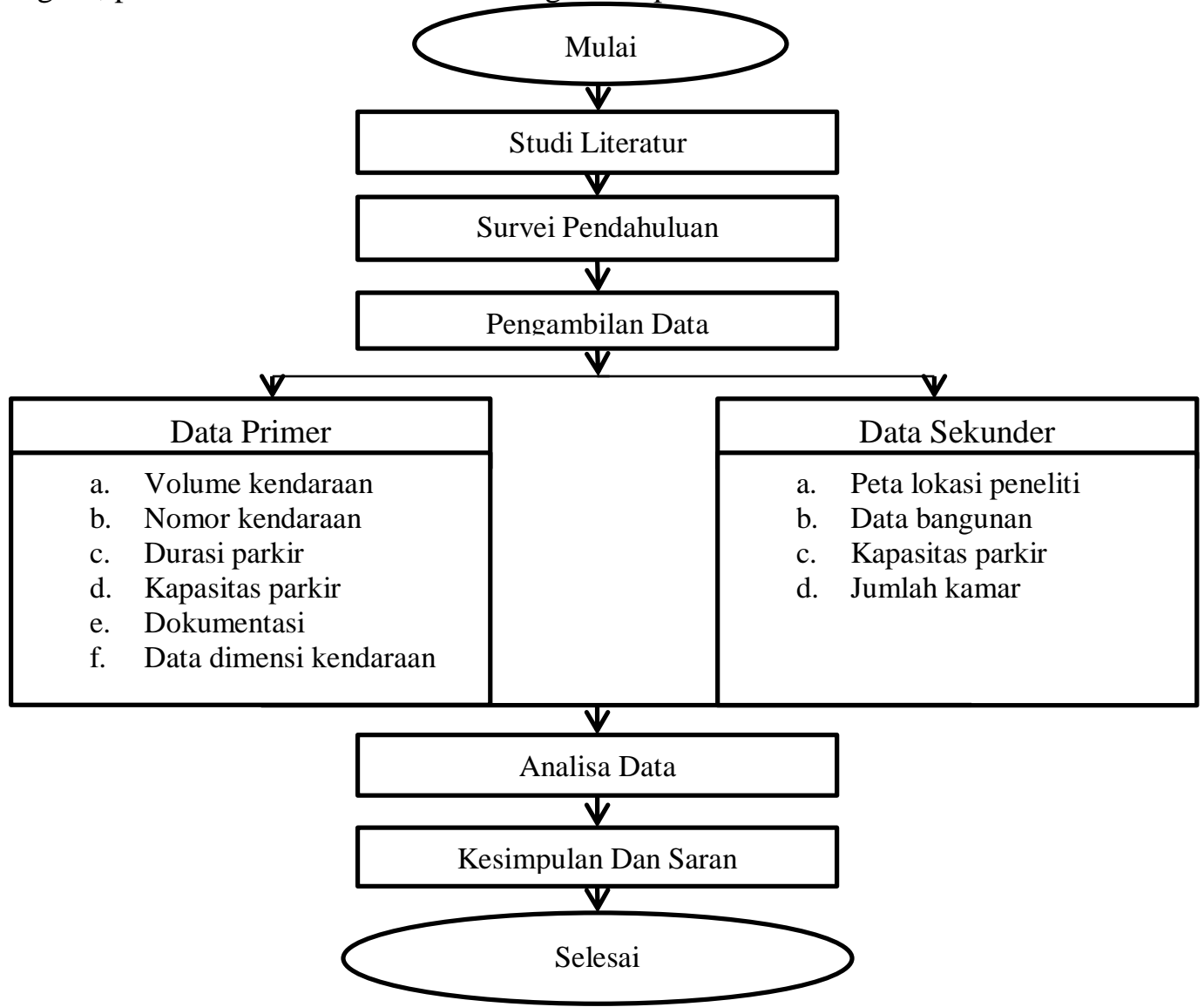

Gambar 2. Bagan Alir Penelitia

\section{HASIL DAN PEMBAHASAN}

a. Lokasi survei

Dari keseluruhan lokasi tempat yang dipergunakan dibagian dalam beberapa bagian lokasi sebagai berikut:

Tabel 2. Pembagian lokasi areal parker

\begin{tabular}{|c|c|c|c|}
\hline \multirow[b]{2}{*}{ No } & \multirow[b]{2}{*}{ Lokasi Areal Parkir } & \multicolumn{2}{|c|}{ Jumlah Ruang Parkir } \\
\hline & & $\begin{array}{l}\text { Roda Kendaraan Roda } \\
\text { Empat (Unit) }\end{array}$ & $\begin{array}{l}\text { Roda Kendaraan Roda Dua } \\
\text { (Unit) }\end{array}$ \\
\hline 1 & $\begin{array}{l}\text { (A) Kendaraan Roda Empat (Mobil) di Areal } \\
\text { Besement Hotel Swiss-Bell. }\end{array}$ & 50 & \\
\hline 2 & $\begin{array}{l}\text { (B) Kendaraan Roda Empat (Mobil) di Areal } \\
\text { Depat Hotel Swiss-Bell. }\end{array}$ & 30 & \\
\hline 3 & $\begin{array}{l}\text { (C) Kendaraan Roda Dua (MOTOR) di Areal } \\
\text { Besement Hotel Swiss-Bell }\end{array}$ & & 150 \\
\hline & Jumlah & 80 & 150 \\
\hline
\end{tabular}

Sumber: Hasil Survey, (2019)

b. Hasil survei kendaraan masuk dan keluar lokasi parkir Hotel Swiss-Bell

Tabel 3. Kendaraan Masuk dan Keluar Lokasi Parkir

\begin{tabular}{cccc}
\hline Lokasi Survei & Jumlah Kendaraan & Kendaraan Masuk (Unit) & kendaraan Keluar (Unit) \\
\hline \multirow{2}{*}{ Hotel Swiss-Bell } & Sepeda Motor & 314 & 321 \\
& Mobil & 271 & 292 \\
\hline
\end{tabular}

Sumber: Hasil Survei, (2019) 
c. Dimensi Kendaraan

Survei dimensi kendaraan di ambil dari kendaraan yang dominan parkir dilokasi survei dapat dilihat pada table berikut ini:

Tabel 4. Hasil Survei Dimensi Kendaraan

\begin{tabular}{ccccc}
\hline Jenis Kendaraan & $\begin{array}{c}\text { Rata-Rata } \\
\text { Panjang }(\mathbf{c m})\end{array}$ & Rata-Rata Lebar $(\mathbf{c m})$ & $\begin{array}{c}\text { Rata-Rata Buka Pintu } \\
(\mathbf{c m})\end{array}$ & Total Lebar (cm) \\
\hline Sepeda Motor & 185 & 70 & & \\
Mobil & 450 & 165 & 55 & 220 \\
\hline
\end{tabular}

Sumber: Hasil Survei, (2019)

d. Perhitungan Satuan Ruang Parkir (SRP)

Dalam perhitungan Satuan Ruang Parkir (SRP) untuk kendaraan roda dua dan kendaraaan roda empat disesuaikan dengan ketentuan dengan hasil sebagai berikut :

1. Perhitungan SRP kendaraan roda empat atau mobil :

$$
\begin{aligned}
\mathrm{Bp} & =\mathrm{B}+\mathrm{O}+\mathrm{R} \\
\mathrm{Bp} & =170+75+5 \\
\mathrm{Lp} & =2,5 \mathrm{M} \\
\mathrm{Lp} & =470+10+20 \\
\mathrm{SRP} & =5 \mathrm{M} \\
& =\mathrm{Bp} \times \mathrm{Lp} \\
& =2,5 \times 5=12,5 \mathrm{M}^{2}
\end{aligned}
$$

2. Perhitungan SRP Kendaraan roda dua atau sepeda motor :

$$
\begin{array}{ll}
\mathrm{Bp} & =\mathrm{B}+\mathrm{O} \\
\mathrm{Bp} & =70+5 \\
& =0,75 \mathrm{M} \\
\mathrm{Lp} & =\mathrm{L}+\mathrm{a} 1+\mathrm{a} 2 \\
\mathrm{Lp} & =175+20+5=2 \mathrm{M} \\
\mathrm{SRP} & =\mathrm{Bp} \times \mathrm{Lp} \\
& =2 \times 0,75=1,5 \mathrm{M}^{2} \\
\text { Keterangan: }
\end{array}
$$

$\begin{aligned} \mathrm{B} & =70 \mathrm{~cm} \\ \mathrm{O} & =5 \mathrm{~cm} \\ \mathrm{~L} & =175 \mathrm{~cm} \\ \mathrm{a} 1 & =20 \mathrm{~cm} \\ \mathrm{a} 2 & =5 \mathrm{~cm}\end{aligned}$

e. Durasi Parkir

Tabel 5. Durasi parkir kendaraan paling lama

\begin{tabular}{ccc}
\hline Lokasi Survey & Jenis Kendaraan & Durasi Parkir Maksimum (Jam) \\
\hline Hotel Swiss-Bell & Roda Dua & $11: 52: 00$ \\
& Roda Empat & $10: 14: 00$ \\
\hline
\end{tabular}

Sumber: Hasil Survei, (2019)

\section{Pembahasan}

1. Akumulasi parkir

Akumulasi parkir adalah jumlah kendaraan yang parkir pada suatu saat tertentu, di suatu tempat gedung parkir atau pelantaran parkir, informasi mengenai akumulasi parkir ini digunakan untuk merencanakan ruang parkir yang dibutuhkan, mengambarkan perubahan jumlah kendaraan parkir pada suatu tempat tertentu yang diakibatkan adanya kendaraaan masuk dan keluar areal parkir. 
Tabel 6. Akumulasi parkir kendaraan roda dua

\begin{tabular}{cccccc}
\hline NO & Jam & $\begin{array}{c}\text { Jumlah Kendaraan } \\
\text { Masuk }\end{array}$ & $\begin{array}{c}\text { Jumlah Kendaraan } \\
\text { Keluar }\end{array}$ & Akumulasi & Keterangan \\
\hline 1 & $08: 30-09: 30$ & 58 & 37 & 21 & \\
2 & $09: 30-10: 300$ & 25 & 13 & 33 & \\
3 & $10: 30-11: 30$ & 29 & 14 & 44 & \\
4 & $11: 30-12: 30$ & 19 & 14 & 49 & \\
5 & $12: 30-13: 30$ & 20 & 9 & 60 & \\
6 & $13: 30-14: 30$ & 22 & 19 & 63 & Jumlah Kendaraan Paarkir \\
7 & $14: 30-15: 30$ & 21 & 16 & 68 & Sebelum Jam 08:30:00=27 \\
8 & $15: 30-16: 30$ & 14 & 15 & 70 & bh kendraan \\
9 & $16: 30-17: 30$ & 16 & 13 & 70 & \\
10 & $17: 30-18: 30$ & 18 & 18 & 76 & \\
11 & $18: 30-19: 30$ & 37 & 31 & 48 & \\
12 & $19: 30-20: 30$ & 30 & 39 & 16 & \\
13 & $20: 30-21: 30$ & 13 & 32 & 0 & \\
14 & $21: 30-22: 30$ & 29 & 61 & $\mathbf{7 5 2}$ & \\
15 & $22: 30-23: 30$ & 0 & 30 & $\mathbf{5 0}$ & \\
\multicolumn{7}{l}{ Rata-Rata/Jam } & $\mathbf{3 6 1}$ & $\mathbf{2 4}$ & &
\end{tabular}

Sumber: Hasil Survei, (2019)

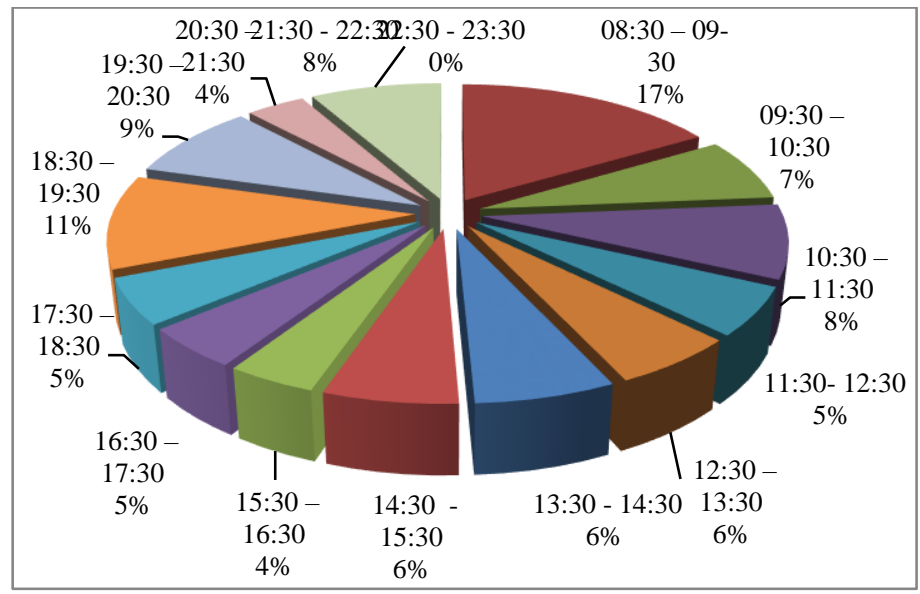

Sumber: Hasil Survei (2019).

Gambar 3. Jumlah Persen (\%) Kendaraan Masuk, Kendaraan Keluar, Akumulasi Parkir Jenis Kendaraan Roda Dua

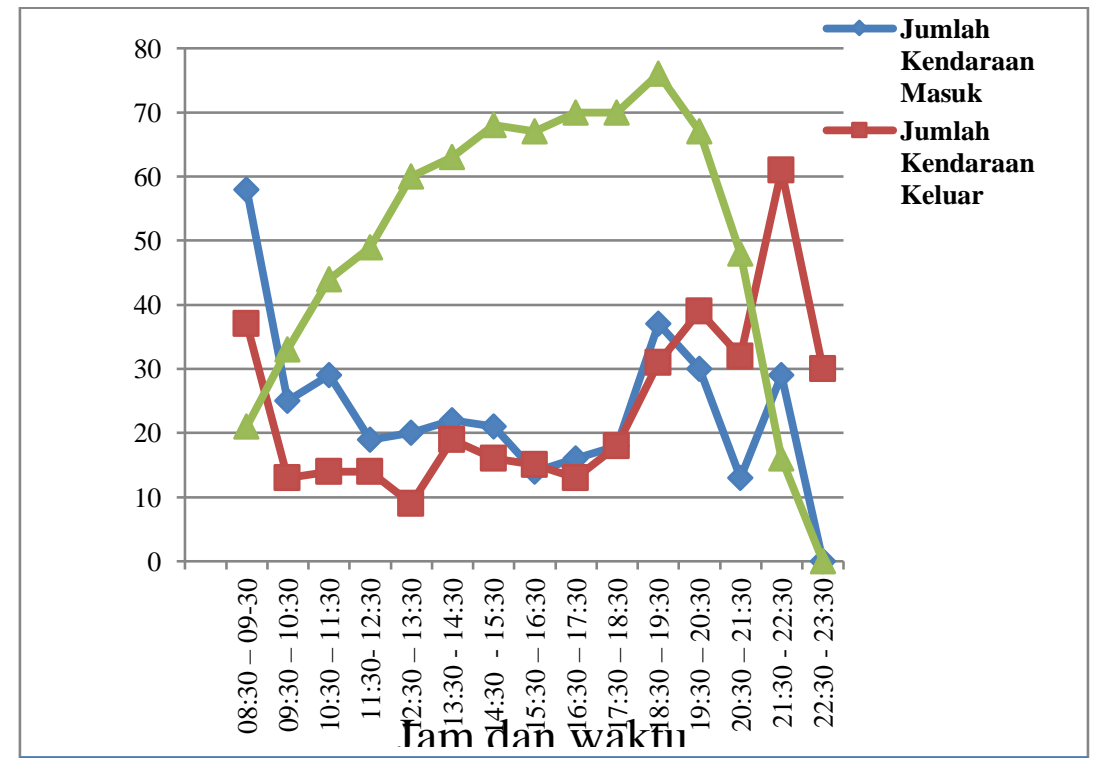

Sumber: Hasil Survei (2019)

Gambar 4. Gerafik Kendaraan Masuk, Kendaraan Keluar, Akumulasi Parkir Jenis Kendaraan Roda Dua 
Tabel 7. Akumulasi parkir kendaraan roda dua

\begin{tabular}{cccccc}
\hline NO & Jam & $\begin{array}{c}\text { Jumlah Kendaraan } \\
\text { Masuk }\end{array}$ & $\begin{array}{c}\text { Jumlah Kendaraan } \\
\text { Keluar }\end{array}$ & Akumulasi & Keterangan \\
\hline 1 & $08: 30-09: 30$ & 41 & 7 & 34 & \\
2 & $09: 30-10: 300$ & 12 & 7 & 39 & \\
3 & $10: 30-11: 30$ & 21 & 13 & 47 & \\
4 & $11: 30-12: 30$ & 15 & 13 & 49 & \\
5 & $12: 30-13: 30$ & 14 & 11 & 52 & Jumlah Kendaraan Paarkir \\
6 & $13: 30-14: 30$ & 17 & 13 & 56 & Kendraan \\
7 & $14: 30-15: 30$ & 14 & 11 & 59 & \\
8 & $15: 30-16: 30$ & 17 & 27 & 49 & bebelum Jam 08:30:00 \\
9 & $16: 30-17: 30$ & 15 & 16 & 48 & \\
10 & $17: 30-18: 30$ & 12 & 14 & 46 & \\
11 & $18: 30-19: 30$ & 24 & 23 & 59 & \\
12 & $19: 30-20: 30$ & 26 & 24 & 54 & \\
13 & $20: 30-21: 30$ & 29 & 40 & 40 & \\
14 & $21: 30-22: 30$ & 21 & 45 & 0 & \\
15 & $22: 30-23: 30$ & 5 & $\mathbf{2 8 3}$ & $\mathbf{7 3 1}$ & \\
\multicolumn{7}{c}{ Rata-Rata/Jam } & $\mathbf{2 8 3}$ & $\mathbf{1 9}$ & & \\
\hline
\end{tabular}

Sumber: Hasil Survei, (2019)

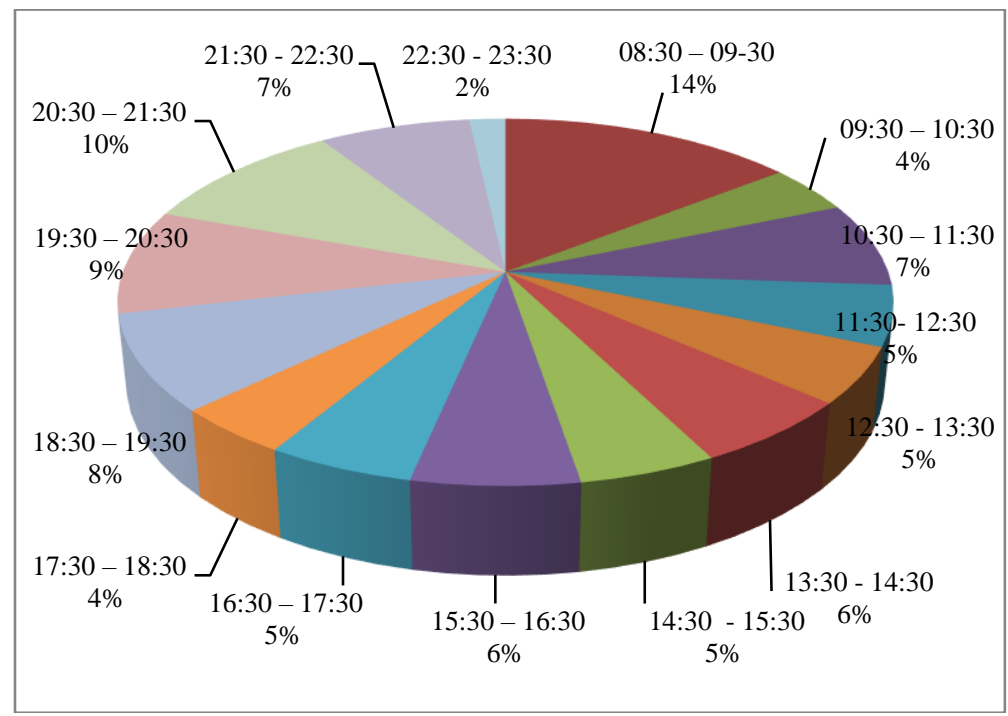

Sumber : Hasil Survei (2019)

Gambar 5. Jumlah Persen (\%) Kendaraan Masuk, Kendaraan Keluar, Akumulasi Parkir Jenis Kendaraan Roda Empat

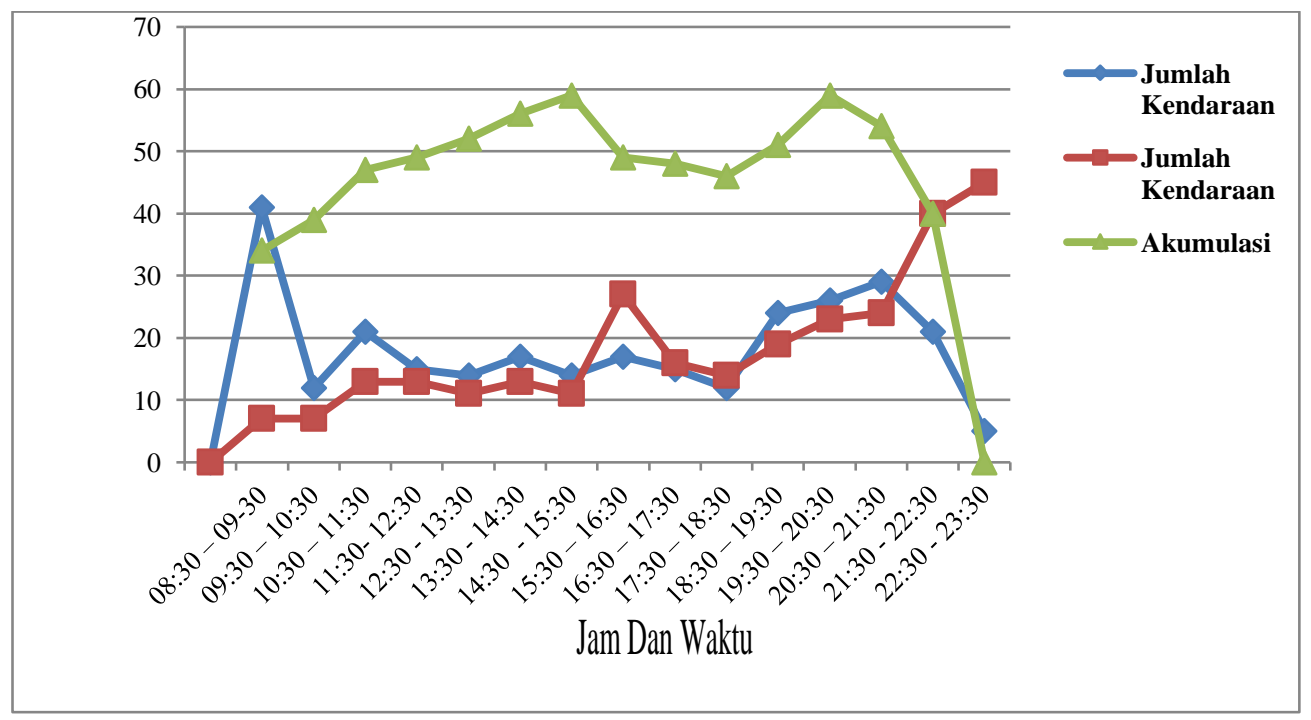

Sumber: Hasil Analisa Survei (2019).

Gambar 6. Grafik Kendaraan Masuk, Kendaraan Keluar, Akumulasi Parkir Jenis Kendaraan Roda Dua 
2. Volume Parkir

Voleme parkir adalah jumlah kendaraan yang masuk areal parkir selama waktu pengamatan, dengan demikian volume parkir merupakan jumlah kendaraan yang masuk areal parkir Hotel Swiss-Bell dianggap menggunakan fasilitas parkir, dimana perhitungannya menggunakan persamaan .

Tabel 8. Volume Parkir

\begin{tabular}{cc}
\hline Jenis Kendaraan & Volume Parkir Kendaraan (Unit) \\
\hline Mobil & 283 \\
Sepeda Motor & 361 \\
Jumlah & 644 \\
\hline
\end{tabular}

Sumber: Hasil Survei, (2019)

\section{Perhitungan ruang berdasarkan jumlah pengguna parkir}

a. Dalam studi ini perhitungan ruang parkir berdasarkan jumlah pengguna parkir diasumsikan jumlah ruang parkir yang ada dikurang jumlah kendaraan yang masuk dikurang jumlah kendaraan yang ada sebelumnya dalam interval waktu 1 (satu) jam dapat dilihat pada tabel berikut ini :

Tabel 9. Jumlah ruang parkir berdasarkan pengguna parkir kendaraan roda dua dalam interval waktu 1 (satu) jam

\begin{tabular}{|c|c|c|c|c|c|}
\hline \multirow[b]{2}{*}{ No } & \multicolumn{4}{|c|}{ Kendaraan Masuk } & \multirow[b]{2}{*}{$\begin{array}{c}\text { Jumlah Ruang Parkir } \\
\text { Yang Tersisa }\end{array}$} \\
\hline & Jam & $\begin{array}{c}\text { Jumlah Ruang } \\
\text { Parkir (Unit) }\end{array}$ & $\begin{array}{c}\text { Jumlah Kendaraaan } \\
\text { Masuk (Unit) }\end{array}$ & $\begin{array}{c}\text { Jumlah Kendaraaan } \\
\text { Parkir Sebelumnya (Unit) }\end{array}$ & \\
\hline 1 & $08: 30-09: 30$ & 150 & 31 & 48 & 71 \\
\hline 2 & 09:30-10:300 & 150 & 25 & 60 & 65 \\
\hline 3 & $10: 30-11: 30$ & 150 & 29 & 75 & 46 \\
\hline 4 & $11: 30-12: 30$ & 150 & 19 & 80 & 51 \\
\hline 5 & $12: 30-13: 30$ & 150 & 20 & 91 & 39 \\
\hline 6 & $13: 30-14: 30$ & 150 & 22 & 94 & 34 \\
\hline 7 & $14: 30-15: 30$ & 150 & 21 & 99 & 30 \\
\hline 8 & $15: 30-16: 30$ & 150 & 14 & 98 & 38 \\
\hline 9 & $16: 30-17: 30$ & 150 & 16 & 101 & 32 \\
\hline 10 & $17: 30-18: 30$ & 150 & 18 & 107 & 25 \\
\hline 11 & $18: 30-19: 30$ & 150 & 37 & 106 & 7 \\
\hline 12 & 19:30-20:30 & 150 & 30 & 97 & 23 \\
\hline 13 & $20: 30-21: 30$ & 150 & 13 & 78 & 59 \\
\hline 14 & $21: 30-22: 30$ & 150 & 29 & 76 & 75 \\
\hline 15 & $22: 30-23: 30$ & 150 & 0 & 16 & 134 \\
\hline
\end{tabular}

Sumber: Hasil Survei, (2019)

Tabel 10. Jumlah ruang parkir berdasarkan pengguna parkir kendaraan roda empat dalam interval waktu 1 (satu) jam

\begin{tabular}{cccccc}
\hline No & Jam & $\begin{array}{c}\text { Kumlah Ruang } \\
\text { Parkir (Unit) }\end{array}$ & $\begin{array}{c}\text { Jumlah Kendaraaan } \\
\text { Masuk (Unit) }\end{array}$ & $\begin{array}{c}\text { Jumlah Kendaraaan } \\
\text { Parkir Sebelumnya (Unit) }\end{array}$ & $\begin{array}{c}\text { Jumlah Ruang Parkir } \\
\text { Yang Tersisa }\end{array}$ \\
\hline 1 & $08: 30-09: 30$ & 80 & 41 & 48 & -9 \\
2 & $09: 30-10: 300$ & 80 & 12 & 53 & 15 \\
3 & $10: 30-11: 30$ & 80 & 21 & 61 & 2 \\
4 & $11: 30-12: 30$ & 80 & 15 & 63 & 6 \\
5 & $12: 30-13: 30$ & 80 & 14 & 60 & -7 \\
6 & $13: 30-14: 30$ & 80 & 17 & 70 & -7 \\
7 & $14: 30-15: 30$ & 80 & 14 & 73 & 0 \\
8 & $15: 30-16: 30$ & 80 & 17 & 63 & 3 \\
9 & $16: 30-17: 30$ & 80 & 15 & 62 & 8 \\
10 & $17: 30-18: 30$ & 80 & 12 & 60 & -9 \\
11 & $18: 30-19: 30$ & 80 & 24 & 65 & -14 \\
12 & $19: 30-20: 30$ & 80 & 26 & 68 & -22 \\
13 & $20: 30-21: 30$ & 80 & 29 & 73 & 5 \\
14 & $21: 30-22: 30$ & 80 & 21 & 54 & 61 \\
15 & $22: 30-23: 30$ & 80 & 5 & 14 & \\
\hline
\end{tabular}

Sumber: Hasil Survei, (2019) 
b. Perhitungan luas ruang parkir

1. Luas ruang parkir untuk kendaraan roda empat yang ada

Luas ruang parkir $=$ SRP Kendaraan roda empat $\mathrm{X}$ Jumlah ruang parkir

Keterangan :

SRP Kendaraan roda empat golongan II $=12,5 \mathrm{M}^{2}$

Jumlah ruang parkir kendaraan roda empat $\quad=80$ ruang parkir

$12,5 \mathrm{M}^{2}$ X $80=1000 \mathrm{M}^{2}$

2. Luas ruang parkir untuk kendaraan roda dua

Luas ruang parkir $=\mathrm{SRP}$ Kendaraan roda empat $\mathrm{X}$ Jumlah ruang parkir

SRP Kendaraan roda dua $\quad=1,5 \mathrm{M}^{2}$

Jumlah ruang parkir kendaraan roda empat $\quad=150$ ruang parkir

$1,5 \mathrm{M}^{2}$ X $150=225 \mathrm{M}^{2}$

Jumlah luas ruang parkir yang ada untuk kendaraan roda dua dan roda empat adalah sebesar : $1225 \mathrm{M}^{2}$

3. Perhitungan pertambahan luas ruang parkir kendaraan roda empat agar kapasitas mencukupi

Luas ruang parkir $=$ SRP Kendaraan roda empat $X$ jumlah ruang parkir

SRP Kendaraan roda empat golongan $\mathrm{II}=12,5 \mathrm{M}^{2}$

Jumlah ruang parkir yang berlebih $=102$ ruang parkir

$12,5 \mathrm{M}^{2}$ X $102=1275 \mathrm{M}^{2}$

Jadi luas pertambahan lahan parkir untu kendaraan roda empat sebesar

$1275 \mathrm{M}^{2} \mathrm{X} 1000 \mathrm{M}^{2}=275 \mathrm{M}^{2}$

\section{Perhitungan ruang parkir kondisi saat ini}

a. Kapasitas ruang parkir

Kapasitas ruang parkir di depan dengan menghitungkan luas areal parkir dikalikan dengan lamanya waktu survei dibagi durasi parkir.

Tabel 11. Kapasitas ruang parkir kondisi saat ini

\begin{tabular}{cccccc}
\hline $\begin{array}{c}\text { Jenis } \\
\text { Kendaraan }\end{array}$ & Durasi Parkir (D) & Lama Survei (P) & $\begin{array}{c}\text { Ruang Parkir (KS) } \\
\text { (Kendaraan) }\end{array}$ & $\begin{array}{c}\text { Kapasitas (KD) } \\
\text { (kendaraan) }\end{array}$ & $\begin{array}{c}\text { Total } \\
\text { (SRP) }\end{array}$ \\
\hline $\begin{array}{c}\text { Roda Dua } \\
\text { Roda Empat }\end{array}$ & $11: 52: 00$ & $15: 00: 00$ & 150 & 195,31 & 195 \\
\hline S & $10: 14: 00$ & $15: 00: 00$ & 80 & 118,34 & 118 \\
\hline
\end{tabular}

Sumber: Hasil Survei,(2019)

b. Jumlah kebutuhan ruang parkir

Untuk menghitung jumlah kebutuhan ruang parkir adalah data primer volume dan data luas areal yang digunakan untuk parkir, kemudian dari data tersebut dapat dihitung jumlah kebutuhan ruang parkir dengan menggunakan persamaan (2.5).

Tabel 12. Jumlah kebutuhan ruang parker

\begin{tabular}{ccccccc}
\hline $\begin{array}{c}\text { Jenis } \\
\text { Kendaraan }\end{array}$ & $\begin{array}{c}\text { Kendaraan } \\
\text { Masuk (x) }\end{array}$ & $\begin{array}{c}\text { Kendaraan } \\
\text { Keluar }(\mathbf{Y})\end{array}$ & $\begin{array}{c}\text { Durasi } \\
\text { Parkir }(\mathbf{D})\end{array}$ & $\begin{array}{c}\text { Lama Survei } \\
(\mathbf{P})\end{array}$ & $\begin{array}{c}\text { Kebutuhan } \\
\text { Parkir }(\mathbf{Z})\end{array}$ & Total SRP \\
\hline Roda Dua & 361 & 361 & $11: 50: 00$ & $15: 00: 00$ & 276,76 & 276 \\
Roda Empat & 283 & 283 & $10: 14: 00$ & $15: 00: 00$ & 189,42 & 191 \\
\hline
\end{tabular}

Sumber: Hasil Survei,(2019)

c. Indeks parkir

Indeks parkir adalah jumlah tempat parkir yang disediakan dengan jumlah kendaraan parkir yang menepati.

Indeks parkir dihitung dengan menggunakan persamaan (2.6).

Tabel 13. Indeks parker

\begin{tabular}{cccccc}
\hline $\begin{array}{c}\text { Jenis } \\
\text { Kendaraan }\end{array}$ & $\begin{array}{c}\text { Kendaraan } \\
\text { Masuk (x) }\end{array}$ & $\begin{array}{c}\text { Kendaraan } \\
\text { Keluar (Y) }\end{array}$ & $\begin{array}{c}\text { Akumulasi } \\
\text { Parkir (A) }\end{array}$ & $\begin{array}{c}\text { Ruang Parkir } \\
(\text { KS) }\end{array}$ & $\begin{array}{c}\text { Indeks Parkir } \\
\text { (IP) }\end{array}$ \\
\hline Roda Dua & 361 & 361 & 752 & 150 & 5,01 \\
Roda Empat & 283 & 283 & 731 & 80 & 9,13 \\
\hline
\end{tabular}

Sumber: Hasil Survei,(2019)

\section{Bangkitan parkir}


Bangkitan parkir dihitung dan jumlah kendaraan yang masuk areal parkir yang dianggap menggunakan fasilitas parkir. Berdasarkan hasil survei dilapangan dapat dilihat pada tabel berikut ini:

Tabel 14. Bangkitan parkir

\begin{tabular}{cc}
\hline Jenis Kendaaran & Bangkitan Parkir (Unit) \\
\hline Sepeda Motor & $283 /$ Hari \\
Mobil & $361 /$ Hari \\
Jumlah & $644 /$ Hari \\
\hline
\end{tabular}

Sumber : Hasil Survei,(2019)

\section{Rekapitulasi hasil perhitungan jumlah ruang parkir}

Tabel 16. Tabel rekapitulasi perhitungan jumlah ruang parkir

\begin{tabular}{|c|c|c|c|c|c|c|c|}
\hline \multirow{3}{*}{ No } & \multirow{3}{*}{ Uraian } & \multicolumn{3}{|c|}{ Jumlah Ruang Parkir } & \multirow{2}{*}{\multicolumn{3}{|c|}{ Kendaraan Roda Empat }} \\
\hline & & Kenda & aaan Roda D & & & & \\
\hline & & Ruang Parkir & Kebutuhan & Kapasitas & Ruang Parkir & Kebutuhan & \\
\hline 1 & $\begin{array}{c}\text { Perhitungan } \\
\text { Berdasarkan Kondisi } \\
\text { Saat Ini }\end{array}$ & 150 & 276 & 195 & 80 & 191 & 118 \\
\hline
\end{tabular}

Sumber: Hasi Survei,(2019)

\section{SIMPULAN}

Dari hasil survei dan analisa yang telah dilakukan pada areal parkir Hotel Swiss-Bell dapat diambil kesimpulan sebagai berikut:

1. Berdasarkan hasil perhitungan kebutuhan ruang parkir di Hotel Swiss-Bell,untuk kendaraan roda dua atau sepeda motor jumlah ruang parkir yang di sediakan 150 ruang parkir dengan luas sebesar $225 \mathrm{M}^{2}$ mampu melayani kapasitas parkir sebesar 195 kendaraan / hari.

2. Untuk kendaraan roda empat jumlah rung parkir yang disediakan 150 ruang parkir dengan luas ruang parkir 1000 $\mathrm{M}^{2}$ mampu melayani kapasitas parkir sebesar 118 kendaraan / hari.

3. Perhitungan kapasitas ruang parkir pada Hotel Swiss-Bell, berdasarkan jumlah kendaraan masuk pada jam sibuk (interval waktu $1 \mathrm{jam}$ ). Untuk kendaraan roda dua puncak tingkat pengguna ruang parkir kendaraan masuk sebesar 37 kendaraan, kendaraan yang ada sebelumnya sebesar 106 kendaraan, ruang parkir yang tersedia 150 ruang parkir, sisa ruang parkir di Hotel Swiss-Bell 7 ruang parkir. Ini menunjukan ruang parkir di Hotel Swiss-Bell mencukupi.

4. Perhitungan kapasitas ruang parkir pada Hotel Swiss-Bell, berdasarkan jumlah kendaraan masuk pada jam sibuk (interval waktu $1 \mathrm{jam}$ ). Untuk kendaraan roda empat puncak tingkat pengguna ruang parkir kendaraan masuk sebesar kendaraan, kendaraan yang ada sebelumnya sebesar 23 kendaraan, ruang parkir yang tersedia 80 ruang parkir, sisa ruang parkir di Hotel Swiss-Bell -22 ruang parkir. Ini menunjukan ruang parkir di Hotel Swiss-Bell tidak mencukupi.

5. Berdasarkan luas rung parkir sebesar $1000 \mathrm{M}^{2}$ untuk kendaraan roda empat yang tersedia hanya mampu menampung kapasitas parkir 118 kendaraan / hari. Untuk itu perlu adanya penambahan lahan parkir minimum 275 $\mathrm{M}^{2}$ supaya bias menampung kendaraan yang parkir.

\section{Saran}

Berdasarkan hasil pengamatan di lapangan dan hasil analisa serta pembahasan, maka penulisan menyarankan sebagai berikut:

1. Berdasarkan hasil perhitungan dan ketentuan yang berlaku mengenai perparkiran, maka perlu adanya pengaturan areal parkir untuk kendaraan roda empat harus ada penambahan kapasitas parkir yang ada di areal parkir Hotel Swiss-Bell.

2. Harus adanya batas atau garis marka parkir yang jelas pada ruang bebas parkir agar para pengemudi yang memakirkan kendaraan bisa tertib dan rapi tidak menganggu pengguna parkir lain.

3. Perlu menambah rambu-rambu untuk menunjukan daerah-daerah lokasi parkir dan daerah larangan parkir dengan penempatan rambu yang mudah terluhat oleh para pengemudi.

4. Pengaturan parkir oleh pengelola parkir ditingkatkan, terutama pada jam-jam sibuk (puncak tertinggi) kendaraan memasuki lahan parkir agar kendaraan tidak menutupi atau menghambat surkulasi kendaraan yang lain. 


\section{DAFTAR PUSTAKA}

Abubakar dkk, 1998, Pedoman Perencanaan dan Pengoperasian Fasilitas Parkir, Edisi I, Direktorat Bina Sistim Lalulintas dan Angkutan Kota, Direktorat Jenderal Perhubungan Darat, Jakarta.

A.A. Jaya Wikrama, 2010, Analisa Karakteristik Dan Kebutuhan Parkir Di Pasar Kreneng, Universitas Udayana, Denpasar.

Ahmad Munawar, 2004, Manajemen Lalulintas Perkotaan. Universitas Gadjah Mada Yogyakarta.

Dewi Sakti, 2011, Analisa Kapasitas Ruang Parkir Mobil Penumpang Off Streetfik dan FT, Universitas Negeri I Semarang.

Direktur Jendral Perhubungan Darat, 1996, Pedoman Penyelenggaraan Fasilitas Parkir, Ditetapkan, Jakarta, Tagal 8 April 1996.

Fauziah Sayarifuddin, 2017, Kebutuhan Ruang Parkir Pada Rumahsakit Bhayangkara, Universitas Islam Negri Alauddin Makassar.

Farisa Rehman, 2011, Analisa Kapasitas Ruang Parkir Sepeda Motor Kawasan FIP,FIS,FE, DAN FH, Universitas Negri Semarang.

I.N Karunia Putra, 2007, Kebutuhan Raung Parkir Kendraan Pengunjung, Universitas Batang Hari Jambi (Tugas Akhir tidak dipublikasikan),Jambi.

Lindawati MZ, 2012, Analisa Kebutuhan Dan Penataan Ruang Parkir, Universitas Baturaja.

Sri Perwani, 2017, Pengertian Perhotelan Secara Umum, Universitas Facilty Of Econimi And Cominication. 